IDDF2018-ABS-0092 CLINICAL, HISTOLOGICAL CHARACTERISTICS AND BRAF MUTATION IN PATIENTS WITH COLORECTAL POLYP IN THAI NGUYEN

Doan Anh Thang*, Luu Thi Binh, Nguyen Trong Hieu, Tran Duc Quy, Dong Duc Hoang. Thai Nguyen University of Medicine and Pharmacy, Vietnam

10.1136/gutjnl-2018-IDDFabstracts. 106

Background BRAF is a localised gene in chromosome $7 \mathrm{q} 34$. The BRAF V600E gene mutation as a necessary starting condition for the transition from benign to malignant lesions is well worth monitoring for prognosis of colorectal lesions.

Aims Describe histopathology and BRAF mutations in colorectal polyps.

Methods A total of 81 patients with non-cancerous colon polyps were randomly assigned to the study. Patients with endoscopic polyps, specimens for histopathology then classify groups: neoplastic, hyperplastic, hamartomatous, inflammatory polyp. The immunohistochemical analysis of these samples then determined the BRAF mutation.

Results The percentage of male is $69.1 \%$, female is $30.9 \%$. The mean age was $52.06 \pm 12.83$. Adenoma polyps accounted for $63 \%$. Serrated polyps were 35.8 . Juvenile polyps had a ratio of $1.2 \%$. Mild dysplasia is $58 \%$, moderate dysplasia is $6.2 \%$, severe dysplasia is $3.7 \%$. BRAF gene mutation accounted for $22.2 \%$, pervasive sample was highest with $19.8 \%$, surface and bottom samples were 1.2\%. BRAF gene mutations were detected in $12.5 \%$ hyperplastic polyp, $33.3 \%$ sessile serrated polyps, $100 \%$ traditional serrated adenomas, $p=0.01$. A total of $73 / 81$ specimens were found to be inflammatory in which the BRAF mutation level + was detected in $86.7 \%$ of samples with inflammation, the level of ++BRAF gene mutation detected in $33.3 \%$ of samples have inflammation, $\mathrm{p}=0.003$.

Conclusions BRAF gene mutations in serrated polyps were higher in hyperplastic polyps. This explains the notion that progression from hyperplastic polyps to serrated adenomas with BRAF mutations can lead to colorectal cancer.

\section{IDDF2018-ABS-0093 SAFETY AND DEFECATION STIMULATION BY ROYAL THAI ABDOMINAL MASSAGE}

${ }^{1}$ Uthaiwon Mingmaneeanulek*, ${ }^{2}$ Nuchlada Rojjanapraphaphun, ${ }^{3}$ Sumruang Hunsuan, ${ }^{3}$ Patcharin Rattanavijit, ${ }^{4}$ Krit Pongpirul. 'Ban Khlongrang Health Promotion Hospital, Srimahaphote, Prachinburi, Thailand; ${ }^{2}$ Prachinburi Provincial Health Office, Prachinburi, Thailand; ${ }^{3}$ Srimahaphote Hospital, Prachinburi, Thailand; ${ }^{4}$ Chulalongkorn University, Thailand

\subsection{6/gutjnl-2018-IDDFabstracts. 107}

Background Evidence to support the efficacy of Royal Thai Abdominal Massage (RTAM) on stimulating defecation has been lacking. This study aims to investigate the safety and defecation stimulation effect of RTAM.

Methods One hundred patients, aged at least 32 years, with constipation symptom, underwent $105 \mathrm{~min}$ RTAM by a professional masseuse from March 1 to September 30, 2017. Defecation behaviour diary was given and filled by the subjects. Data were analysed by using descriptive statistics. Thai Clinical Trials Registry No. TCTR20170817004.

Results Of 100 subjects, 51\% could defecate within 24 hours after the RTAM session, of which 15 could defecate within an hour after treatment. The other $49 \%$ could finally defecate in less than 72 hours after the RTAM session. No subjects experienced adverse event or injury.

Conclusions Royal Thai Abdominal Massage is safe and can effectively stimulate defecation in constipated patients. Further studies should be conducted to compare with medical treatment.

\section{IDDF2018-ABS-0095 THE SOCIAL EPIDEMIOLOGICAL FACTORS LINKED WITH INTESTINAL PROTOZOA INFECTION IN DEPOK, EAST JAVA, INDONESIA}

${ }^{1}$ Daniel Martin Simadibrata*, ${ }^{1}$ Timotius Alvonico, ${ }^{2}$ Murdani Abdullah, ${ }^{2}$ Ari Fahrial Syam, ${ }^{3}$ Agnes Kurniawan, ${ }^{2}$ Dadang Makmun. ${ }^{1}$ Faculty of Medicine, University of Indonesia, Indonesia; ${ }^{2}$ Division of Gastroenterology, Department of Internal Medicine, Faculty of Medicine, University of Indonesia, Indonesia; ${ }^{3}$ Department of Parasitology, Faculty of Medicine, University of Indonesia, Indonesia

\subsection{6/gutjnl-2018-IDDFabstracts. 108}

Background Intestinal protozoa infection consists of infection from Giardia lamblia and Blastocystis hominis. The occurrence is linked with poor personal hygiene, poor sanitation facilities and low education level. Previous studies have reported inconsistent results regarding the prevalence of intestinal protozoa infection. However, the prevalence of intestinal protozoa infection in the urban area of Indonesia has yet to be performed. Therefore, the aim of this study was to determine the prevalence of intestinal protozoa infections in urban region of Indonesia and the contributing sociodemographic factors.

Methods A cross-sectional study was performed among 278 healthy inhabitants in Depok from January to March 2012. Screening for protozoa infection was done through stool sample analysis, in which positive results are indicated by finding cysts or trophozoites.

Results Among the 278 subjects, the overall prevalence of protozoa infections was $12.59 \%, 88.57 \%$ of which was due to Blastocystis hominis. The sociodemographic factor that is significantly associated with the occurrence of intestinal protozoa infection was low BMI level. The normal BMI and obese BMI subjects were at a 0.417 and 0.174 risk of presenting with protozoa infection, respectively, compared to low BMI. The underlying mechanisms include increased bowel permeability and impairment of bowel barrier function, lower IgA antibody level, and villous atrophy.

Conclusions Low BMI level was correlated with increased prevalence of protozoa infection in urban region of Indonesia, Depok.

\section{IDDF2018-ABS-0099 COMPARISON OF TWO METHODS FOR ENDOSCOPIC FULL-THICKNESS RESECTION OF GASTROINTESTINAL LESIONS USING OVER-THE-SCOPE CLIP SYSTEM}

Wenhai Wang*, Peng Li, Ming Ji, Yongjun Wang, Shengtao Zhu, Lihua Liu. Beijing Friendship Hospital, Capital Medical, China

\subsection{6/gutjn|-2018-IDDFabstracts. 109}

Background The over-the-scope clip (OTSC) system was developed not only for the closure of gastrointestinal defects but can also be used to assist endoscopic resection. The aim of this study was to compare and analyse the feasibility and safety of two methods of EFTR for the management of 